\title{
AN INTEGRATED MODEL FOR EXTENDING BRAND BASED ON FUZZY ARAS AND ANP METHODS
}

\section{Mahmoud Zamani ${ }^{1}$, Arefeh Rabbani ${ }^{2}$, Abdolreza Yazdani-Chamzini ${ }^{3}$, Zenonas Turskis ${ }^{4}$}

${ }^{1,2}$ Young Researchers Club, Central Tehran Branch, Islamic Azad University, Teheran, Iran

${ }^{3}$ Young Researchers Club, South Tehran Branch, Islamic Azad University, Teheran, Iran

${ }^{4}$ Department of Construction Technology and Management, Faculty of Civil Engineering, Vilnius Gediminas Technical University, Sauletekio al. 11, LT-10223 Vilnius, Lithuania

E-mails: ${ }^{1}$ mahmoudzamani51@gmail.com; ${ }^{2}$ rabbani1365@yahoo.com; 3abdalrezaych@gmail.com; ${ }^{4}$ zenonas.turskis@vgtu.lt (correspondingauthor)

Received 06 November 2013; accepted 09 May 2014

\begin{abstract}
Brand extension is one of the most popular strategies in marketing. This is due to the fact that consumers usually take into account the brand first because it indirectly reflects the design, quality, and functions. According to the significant role of brand in creating benefit and diminishing risk for a new product, this study intended to develop a novel model for selecting the most appropriate strategy in brand extension. However, there are a number of criteria influencing the possible strategies, and they often are interdependent. Therefore, a multi-criteria decision making model based on Analytic Network Process and Additive Ratio Assessment methods has been developed to systematically clarify the interdependent relationships among the evaluation criteria of brand extension and then, scientifically evaluate the feasible strategies and rank the priorities of brand extension strategies. The results of the proposed model show that "Production cost" is the most important factor, followed by "Quality of parent brand" and "Perceived risk" while "Ice cream" is the highest satisfaction of brand extension.
\end{abstract}

Keywords: brand extension, MCDM, ARAS, ANP, fuzzy, model.

Reference to this paper should be made as follows: Zamani, M.; Rabbani, A.; YazdaniChamzini, A.; Turskis, Z. 2014. An integrated model for extending brand based on fuzzy ARAS and ANP methods, Journal of Business Economics and Management 15(3):403-423.

JEL Classification: M21, M31, M37, O16, O22.

\section{Introduction}

Brand extension, defined as the use of an established brand name for new-product categories, is one of the most common strategies used in developing an existing brand, which can reduce risk and increase investment by enhancing consumer perception. Brand extension strategies are beneficial because they reduce new product introduction costs, and perceived risk of the new product, hence increasing the chances of success 
(Aaker 1990; Keller 1998). Approximately 80\% of new products introduced each year are brand extensions (Keller 1998). This is due to the fact that launching a new product is not only time consuming; but also, needs a big budget to create awareness and to promote a product's benefits (Tauber 1981). On the other hand, a victorious brand can help a company to more easily launch new products in novel categories.

Generally, two main advantages of brand extensions could be underlined: the ability to facilitate new-product acceptance; and provide positive feedback to the parent brand and company ${ }^{1}$. Therefore, it is important for marketing researchers and brand managers to understand how consumers evaluate them (Estes et al. 2012). A successful brand message strategy relies on a congruent communication and a clear brand image (Sjodin, Torn 2006).

Although there are significant benefits in brand extension strategies, there are also significant risks, resulting in a diluted or severely damaged brand image. Poor choices for brand extension may dilute and deteriorate the core brand and damage the brand equity (Aaker 1990). In spite of the positive impact of brand extension, negative association and wrong communication strategy do harm to the parent brand and even the brand family (Tauber 1981; Aaker 1990). Therefore, for propose of decreasing the level of risk in the process of brand extension, it is necessary to take into account both qualitative and quantitative parameters influencing the problem in order to get the deeper insight into the problem area. This helps an organisation to properly model the problem of brand extension.

On the other hand, the merit of using multi-criteria decision making (MCDM) techniques is to model a complex and sophisticated problem by applying a well-organised and systematic approach. The MCDM methods provide tools for considering both tangible and intangible parameters involved in the process of modelling in order to make a proper and accurate decision. These methods are strongly recommended as helpful in reaching important decisions that cannot be determined in a straightforward manner (Wu et al. 2010; Fouladgar et al. 2012). Different MCDM techniques have been developed to solve multi criteria problems. These methods can be classified into three main categories (Belton, Stewart 2002): (i) value measurement model such as analytical hierarchy process (AHP), (ii) outranking models such as Preference Ranking Organisation METHod for Enrichment Evaluation (PROMETHEE), and (iii) goal aspiration and reference level models such as Technique to Order Preference by Similarity to Ideal Solution (TOPSIS) and Additive Ratio Assessment Method (ARAS).

ARAS, first introduced by Zavadskas and Turskis (2010), is a branch of the MCDM techniques that solve a complex problem by using simple relative comparisons. This method uses the basic concept of degree of optimality for selecting the best alternative among a pool of alternatives by calculating the ratio of the sum of normalized and weighted criteria scores to the sum of the values of normalized and weighted criteria. The ARAS method is employed by different researchers to rank the possible alterna-

1 www.citeman.com 
tives in order to select the best ones (Zavadskas et al. 2010; Zavadskas, Turskis 2010; Bakshi, Sarkar 2011; Bakshi, Sinharay 2011; Dadelo et al. 2012; Zavadskas et al. 2012; Kutut et al. 2013). This is due to the fact that the ARAS method has several advantages: (i) the computations defined in the process of modelling a decision making problem are straightforward, (ii) the concepts have a profound logic (iii) this method contains a simple mathematical form in the pursuit of the best alternative, and (iv) the relative weights are incorporated into the comparison procedures.

However, ARAS is not capable of facing the vagueness and uncertainty derived from subjective judgments and/or lack of information and/or incomplete data; so that failure to consider the inherent uncertainty and/or imprecision of the elements could result in unreliable and unrealistic assessment. The merit of using fuzzy logic is to take the existing uncertainty into account. This technique uses a linguistic variable instead of the traditional quantitative expression, which is a very helpful concept for dealing with the unknown and complex situations (Zadeh 1965). The combination of fuzzy logic and ARAS technique, known as fuzzy ARAS, is a strategic methodology used for solving the aforementioned problems. Since the fuzzy ARAS contains simple and fast computations, logical process, and tolerating the uncertainty, is recently employed for formulating different aspects of priority problems (Turskis, Zavadskas 2010; Turskis et al. 2012).

However, the main limitation of the fuzzy ARAS method is in formulating a decision making problem without taking into account the interdependency among the evaluation criteria. In the system of real-life problems, the evaluation criteria are strongly interdependent. To take the interrelationship among the elements into account, different models have been developed. Analytic network process (ANP) is one of the most popular techniques in formulating the mutual relationship among the elements. This technique interprets the interrelationship between weights of relationship. This method is employed by a large number of researchers owing to its particular strengths. The reasons for using an ANP-based decision analysis approach are: (1) ANP can measure all tangible and intangible criteria in the model (Saaty 1996), (2) ANP is a relatively simple, intuitive approach that can be accepted by managers and other decision-makers (Presley, Meade 1999), (3) ANP allows for a more complex relationship between the decision levels and attributes as it does not require a strict hierarchical structure (Yazgan et al. 2010), and (4) ANP is more adapted to real world problems (Fouladgar et al. 2012).

On the other hand, in the case of complex problems, it is usually better to use opinions of a group of experts because it is difficult for a single person to possess knowledge and experience in all details of the problem (Sotirov, Krasteva 1994).

The main objective of the current study is to model a brand extension problem as a MCDM problem and provide a three-step decision support framework to accurately evaluate the possible alternatives. For achieving the aim, after defining the problem under consideration and identifying the evaluation criteria and feasible alternatives, the ANP method is employed for obtaining the relative weights of the evaluation criteria but not the entire evaluation process to reduce the large number of pairwise comparison. For this reason, fuzzy ARAS is used to calculate the performance of alternatives, and 
to prioritize the feasible strategies in terms of their overall performance on evaluation main and sub-criteria.

The paper is organized as follows. Section 1 presents a brief overview of the ANP methodology. Section 2 explains the basic concepts of fuzzy logic and the uncertainty involved in the process of decision making. This section also goes one step beyond and examines the steps of the fuzzy ARAS technique. The proposed model is clearly presented in section 3. An application of the proposed model is illustrated in section 4 . Finally, conclusions are discussed in the last section.

\section{Analytic network process (ANP)}

The Analytic network process (ANP), firstly introduced by Saaty (1996), is a generalization of the AHP technique. The AHP technique models a complex problem by decomposing the problem into a hierarchical structure, in which the elements of decision are independent and the relationship between the levels of decision are linear; so that, it ignores interrelationships among the elements. Figure 1 illustrates the difference between hierarchy and network structures. As shown in Figure 1, a hierarchy is a linear top down structure and network is a non-linear structure that spreads out in all directions. An ANP system uses arcs to show the relationships among elements, where the directions of arcs signify directional dependence (Chung et al. 2005). The ANP technique extends the AHP to facilitate the process of formulating the problems with feed-back and dependence (Fouladgar et al. 2012). This method replaces the hierarchy in the AHP with a network to equip the ANP for modelling the interrelationships among decision elements in order to solve the problems that are nonlinear and more complex. Thus, the ANP produces priorities or relative importance of elements in a complex network model with consideration of inter-dependency among elements (Lee et al. 2012).

Like with AHP, pairwise comparison in ANP is performed in the framework of a matrix, and a local priority vector can be derived as an estimate of the relative importance associated with the elements (or clusters) being compared by solving the following equation (Yüksel, Dağdeviren 2007):

$$
A \times w=\lambda_{\max } \times w
$$

where $A$ is the matrix of pairwise comparison, $w$ is the eigenvector, and $\lambda_{\max }$ is the largest eigenvalue of $A$.

In this paper, the hierarchy and network model proposed for modelling the mutual relationships among the benefit, opportunity, cost, and risk (BOCR) parameters including four levels (see Fig. 2).

In the first level, the optimum brand extension strategy (the goal) is located, the BOCR parameters (main criteria) and the BOCR sub-factors (sub-criteria) are situated in the second and third levels, respectively, and the brand extension strategies (alternatives) are located in the last level. The structure of a supermatrix - a matrix of the influences among the elements - for the BOSR network with four levels can be defined as follows: 
A

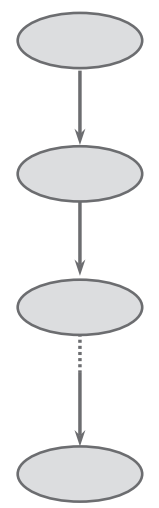

B

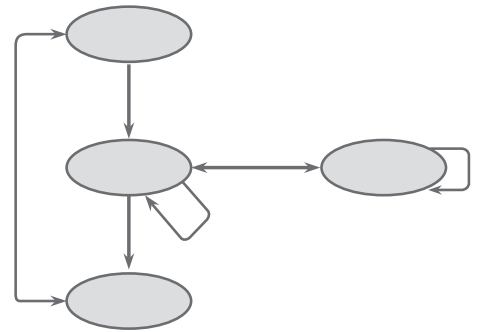

Fig. 1. Difference between a hierarchy (A) and a network (B) (Azimi et al. 2011)

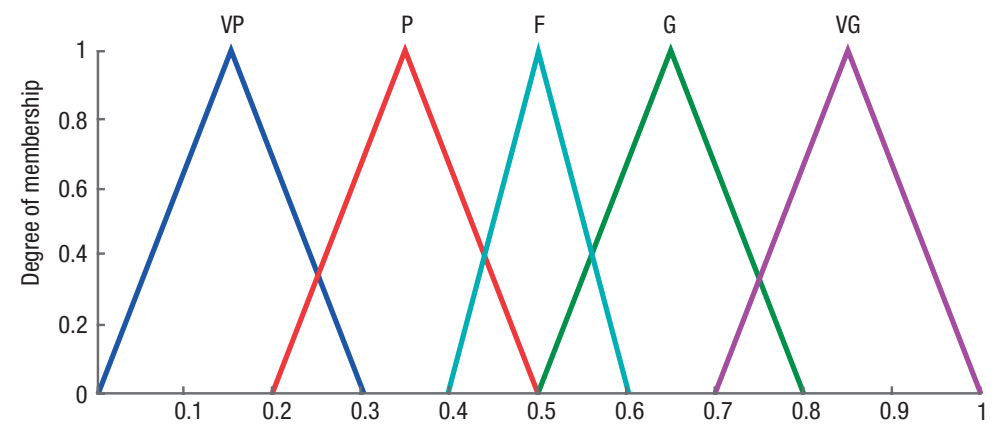

Fig. 2. Membership function of linguistic variables for preference rating

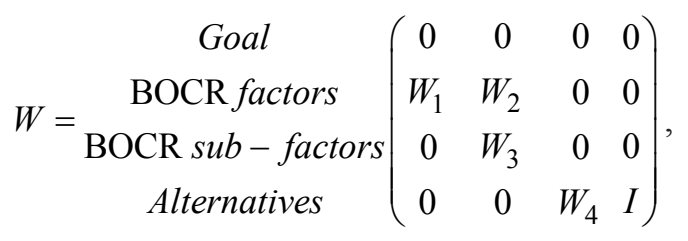

where $W_{1}$ is a matrix that reflects the impact of the overall purpose (selecting the optimal brand extension strategy) on the main criteria (BOCR factors); $W_{2}$ is the matrix that represents the impact of each of the main criteria on each other or inner independence of the BOCR factors; $W_{3}$ is the vector that shows the impact of the main criteria (BOCR factors) on each of the sub-criteria (BOCR sub-criteria); $W_{4}$ is the matrix that reflects the impact of the sub-criteria (BOCR sub-criteria) on each of the alternatives; and $I$ is the identity matrix.

In order to perform the ANP methodology for obtaining the importance weights of the BOCR factors, the algorithm employed is stepwise as follows: 
Step 1. Define the problem and identify the factors having an inner dependency with each other.

Step 2. Without taking into account the dependence among the BOCR factors; calculate the importance weights of the factors with a Saaty's (1-9) scale (Saaty 1980). This means that the process of this step leads to $W_{1}$ be acquired.

Step 3. Calculate the inner dependence matrix of each BOCR factor with respect to the other factors with a 1-9 scale. This means that this step calculates the $W_{2}$ matrix.

Step 4. Measure the interdependent priorities of the BOCR factors. Calculating $W_{f a c-}$ tors $=W_{1} \times W_{2}$ is performed in this step.

Step 5. Calculate the local importance weights of the BOCR sub-factors with a 1-9 scale. $W_{\text {sub-factors (local) }}$ is obtained in this step.

Step 6. Measure the global importance weights of the BOCR sub-factors by multiplying the values of steps 4 and $5\left(W_{\text {sub-factors (global) }}=W_{\text {factors }} \times W_{\text {sub-factors (local) }}\right)$.

\section{Fuzzy ARAS technique}

Additive Ratio Assessment (ARAS), introduced by Zavadskas and Turskis (2010), is based on the concept that the phenomena of complicated world could be understood by using simple relative comparisons (Turskis, Zavadskas 2010). The ARAS method not only determines the performance of alternatives, but also calculates ratio of each alternative to the ideal alternative.

According to the basic concepts of the ARAS method, decision team assigns the relative importance of the evaluation criteria and ratings of the feasible alternatives with respect to the criteria under consideration by using numerical values. In real world problems, it is often difficult for a decision maker to determine precise weights for criteria and alternatives with respect to the criteria under consideration (Yazdani-Chamzini, Yakhchali 2012). The merit of using a fuzzy approach is to determine the importance or preference of criteria and alternatives using fuzzy numbers instead of crisp numbers to be more adapted to the real world cases. Therefore, fuzzy logic and ARAS technique are combined in the form of the fuzzy ARAS method to formulate the real world problems more accurately. The fuzzy ARAS technique helps the decision team to conduct a comprehensive analysis for prioritizing the preference of the alternatives in presence of vague or imprecise information. The procedure of fuzzy ARAS can be defined as follows.

Table 1. Linguistic variables for the rating of alternatives

\begin{tabular}{lc}
\hline Linguistic variables & Triangular fuzzy number \\
\hline Very poor $(\mathrm{VP})$ & $(0,0.15,0.3)$ \\
\hline Poor $(\mathrm{P})$ & $(0.2,0.35,0.5)$ \\
\hline Fair $(\mathrm{F})$ & $(0.4,0.5,0.6)$ \\
\hline Good $(\mathrm{G})$ & $(0.5,0.65,0.8)$ \\
\hline Very good $(\mathrm{VG})$ & $(0.7,0.85,1)$ \\
\hline
\end{tabular}


Step 1. Choose the linguistic rating, $\tilde{x}_{i j}: i=1,2, \ldots, m ; j=1,2, \ldots, n$ for alternatives with respect to criteria under consideration. The values given in Table 1 and Figure 2 present the linguistic ratings applied for alternatives.

Step 2. Form the fuzzy decision matrix. Fuzzy ARAS solves a problem with $m$ alternatives evaluated based on $n$ dimensions. In order to construct the fuzzy ARAS matrix, first a judgment matrix is established as:

$$
\tilde{X}=\left[\begin{array}{ccccc}
\tilde{x}_{01} & \cdots & \tilde{x}_{0 j} & \cdots & \tilde{x}_{0 n} \\
\vdots & \ddots & \vdots & \ddots & \vdots \\
\tilde{x}_{i 1} & \cdots & \tilde{x}_{i j} & \cdots & \tilde{x}_{i n} \\
\vdots & \ddots & \vdots & \ddots & \vdots \\
\tilde{x}_{m 1} & \cdots & \tilde{x}_{m j} & \cdots & \tilde{x}_{m n}
\end{array}\right]
$$

where $\tilde{x}_{i j}$ is fuzzy value representing the preference of the $i$ alternative in terms of the $j$ criterion; $\tilde{x}_{0 j}$ is the optimal value of the $j$ criterion.

Step 3. Aggregate the ratings of alternatives respect to each criterion $\left(\tilde{x}_{i j}\right)$. In order to aggregate the ratings of alternatives versus each criterion, the arithmetic mean is applied.

Let the fuzzy ratings of all decision makers be Triangular Fuzzy Numbers (TFNs) $\tilde{x}_{i j k}=\left(a_{i j k}, b_{i j k}, c_{i j k}\right), k=1,2, \ldots, K$, which $\tilde{x}_{i j k}$ represents the value of the $i$-th alternative respect to the $j$-th criterion by $k$-th decision maker. Then the aggregated fuzzy rating can be defined as:

$$
\tilde{x}_{i j}=\left(a_{i j}, b_{i j}, c_{i j}\right), \quad k=1,2, \ldots, K,
$$

where

$$
a_{i j}=\frac{1}{K} \sum_{k=1}^{K} a_{i j k}, b_{i j}=\frac{1}{K} \sum_{k=1}^{K} b_{i j k}, c_{i j}=\frac{1}{K} \sum_{k=1}^{K} c_{i j k} .
$$

Step 4. Calculate the optimal value of $j$ criterion. It's optimal value is unknown, then it can be obtained by using the following equations:

$$
\begin{aligned}
& \tilde{x}_{o j}=\max _{i} \tilde{x}_{i j} ; \text { The larger, the better type, } \\
& \tilde{x}_{o j}=\min _{i} \tilde{x}_{i j} ; \text { The smaller, the better type. }
\end{aligned}
$$

Step 5. Normalize the decision matrix. The ratio to the optimal value is used to avoid the difficulties caused by different dimensions of the criteria. Several algorithms are developed for calculating the ratio to the optimal value. However, the values are usually transferred into the closed interval 0 and 1 . The matrix resulted from the normalization process can be defined as follows: 


$$
\tilde{\bar{X}}=\left[\begin{array}{ccccc}
\tilde{\bar{x}}_{01} & \ldots & \tilde{\bar{x}}_{0 j} & \ldots & \tilde{\bar{x}}_{0 n} \\
\vdots & \ddots & \vdots & \ddots & \vdots \\
\tilde{\bar{x}}_{i 1} & \ldots & \tilde{\bar{x}}_{i j} & \ldots & \tilde{\bar{x}}_{i n} \\
\vdots & \ddots & \vdots & \ddots & \vdots \\
\tilde{\bar{x}}_{m 1} & \ldots & \tilde{\bar{x}}_{m j} & \ldots & \tilde{\bar{x}}_{m n}
\end{array}\right]
$$

The criteria, whose preferable values are maxima, are normalized as follows (Turskis, Zavadskas 2010):

$$
\tilde{\bar{x}}_{i j}=\frac{\tilde{x}_{i j}}{\sum_{i=0}^{m} \tilde{x}_{i j}} .
$$

The criteria, whose preferable values are minima, are normalized using a two-stage procedure:

$$
\tilde{x}_{i j}=\frac{1}{\tilde{x}_{i j}^{*}} ; \tilde{\bar{x}}_{i j}=\frac{\tilde{x}_{i j}}{\sum_{i=0}^{m} \tilde{x}_{i j}} .
$$

After normalizing the values, the dimensionless values of the criteria are comparable.

Step 6. Calculate the weighted normalized decision matrix. The weighted normalized value is calculated by multiplying the weights of the criteria under consideration $\left(w_{j}\right)$ with the normalized fuzzy decision matrix derived from the previous step. The weighted normalized decision matrix is calculated by the following relations:

$$
\tilde{\hat{x}}_{i j}=\tilde{\bar{x}}_{i j} w_{j} \text {. }
$$

Step 7. Measure the optimality function. The following equation is employed for determining the values of optimality function of $i$-th alternative (Turskis, Zavadskas 2010):

$$
\tilde{S}_{i}=\sum_{j=1}^{n} \tilde{\hat{x}}_{i j} .
$$

The biggest value for $\tilde{S}_{i}$ is the best, and the least one is the worst.

Step 8. Defuzzify the values of optimality function. The output obtained for each alternative is a fuzzy number. Therefore, it is necessary to convert fuzzy numbers into crisp numbers by defuzzification in order to compare the rank of dimensions. The procedure of defuzzification is to locate the Best Nonfuzzy Performance (BNP) value. Methods of such defuzzified fuzzy ranking generally include mean of maximal (MOM), centre of area (COA), and a-cut (Chen et al. 2011). In this study, the authors employ the centre of area (COA) method to prioritize the order of importance of each dimension. This method is a simple and practical without the need to bring in the preferences of any evaluators (Wu et al. 2009). The BNP value for the fuzzy number $\tilde{S}_{i}=\left(L \tilde{S}_{i}, M \tilde{S}_{i}, U \tilde{S}_{i}\right)$ can be found by using the following equation: 


$$
B N P_{i}=\left[\left(U \tilde{S}_{i}-L \tilde{S}_{i}\right)+\left(M \tilde{S}_{i}-L \tilde{S}_{i}\right)\right] / 3+L \tilde{S}_{i} .
$$

Step 9. Calculate the degree of the alternative utility by making a comparison with the optimum one $S_{0}$. The utility degree of an alternative can be calculated by the following Equation:

$$
K_{i}=\frac{S_{i}}{S_{0}}
$$

From the mathematical point of view, the values acquired for $K_{i}$ belong to the range of $[0,1]$.

Step 10. Rank the alternatives according to $K_{i}$ in descending order and select the alternative with maximum value of $K_{i}$.

\section{The proposed model}

The proposed model can be defined as presented in the following steps:

Step 1: Identify the evaluation criteria and classify them based on the BOCR factors.

Step 2: Construct the pairwise comparison matrices based on the scale given in Table 1 for calculating the importance weights of the main and sub-factors. Assume that there is no dependence among the BOCR factors (i.e. construct the AHP model). The local weights of sub-factors arise from this step.

Step 3: Form the pairwise comparison matrices for measuring the relative weights of the BOCR factors (i.e. construct the ANP model). The interdependent weights of the factors are derived from this step.

Step 4: Calculate the global weights of the evaluation indicators by multiplying the weights of the sub-factors obtained in Step 2 with those of the factors to which it belongs and that is acquired in the previous step.

Step 5: Define a linguistic scale for describing the preference ratings of the alternatives. Step 6: Aggregate the fuzzy values resulting from the previous step.

Step 7: Obtain the preference ratings of the alternatives by using the fuzzy ARAS technique based on the global weights yielded in Step 4 and the ratings obtained from the previous step.

Step 8: Prioritize the brand extension strategies in descending order and select the highest rank as the first choice.

The schematic diagram of the proposed model for selecting the optimal brand extension strategy is provided in Figure 3. 


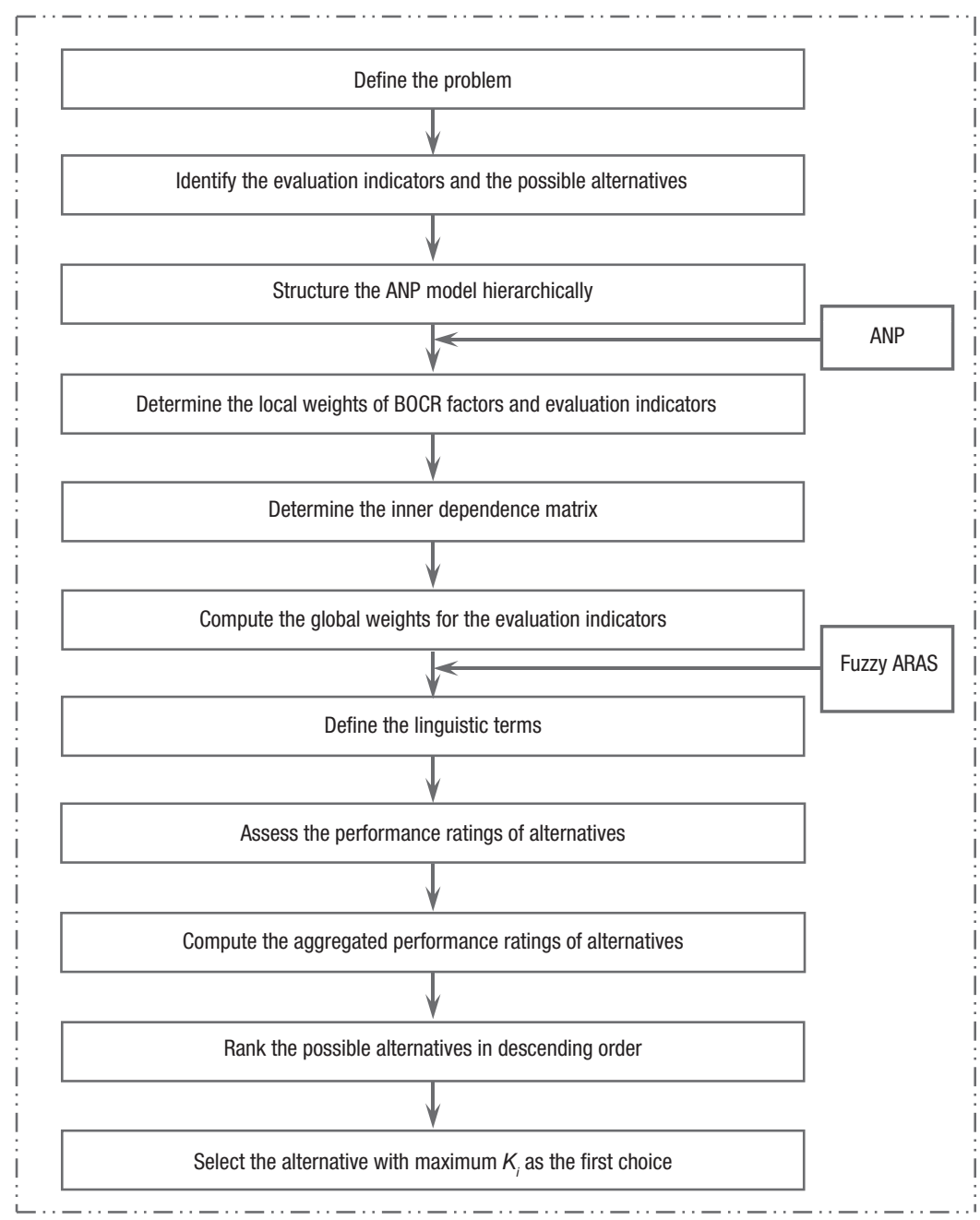

Fig. 3. The outline of the proposed model

\section{An application of the proposed method in food industry}

A manufacturing company desires to select the most appropriate new product to extend its brand into a wide range of new categories and earn money. In order to show the potential application of the proposed model, a stepwise demonstration of methodology is given to exemplify how ANP-ARAS method under fuzzy environment can be used for the evaluation and assessment of the brand extension of food industry in Iran's market. The example is based on a real-world decision problem. Dairy food industry in Iran has been in business for fifty years and has more than 400 sales representatives in the country. From the point of view of production, this company is considered as one of the most important producers. Dairy food industry has a large number of labour force 
in industrial agricultural, commercial and service sections. Therefore, this industry is chosen for the case study.

For achieving the aim, a team of seven evaluators was established, including experts with at least five years of experience in the field of marketing and brand extension. This helps the authorities to appropriately analyse the group decisions (Robbins 1994). The proposed model is described below as a stepwise procedure, based on the steps defined in the previous section.

The priority weights of the evaluation criteria for extending brand are calculated by using the process of the algorithm described in the previous section. After synthesizing the literature review from previous studies, preliminary screening, and a number of face to face interviews with the evaluator team, the four BSC criteria including thirteen sub-criteria, and five feasible alternatives are considered to be involved in the process of the evaluation (see Fig. 4). The four perspectives of the BSC model are applied as a framework of the analysis to help in the definition of the indicators.

In this study, the importance weights of the main and sub-criteria are investigated by distributing questionnaires designed in the format of AHP questionnaire (i.e. pairwise comparisons) and conducting face-to-face interviews with the expert team. The evaluators are asked to determine the importance of the elements in each level with respect

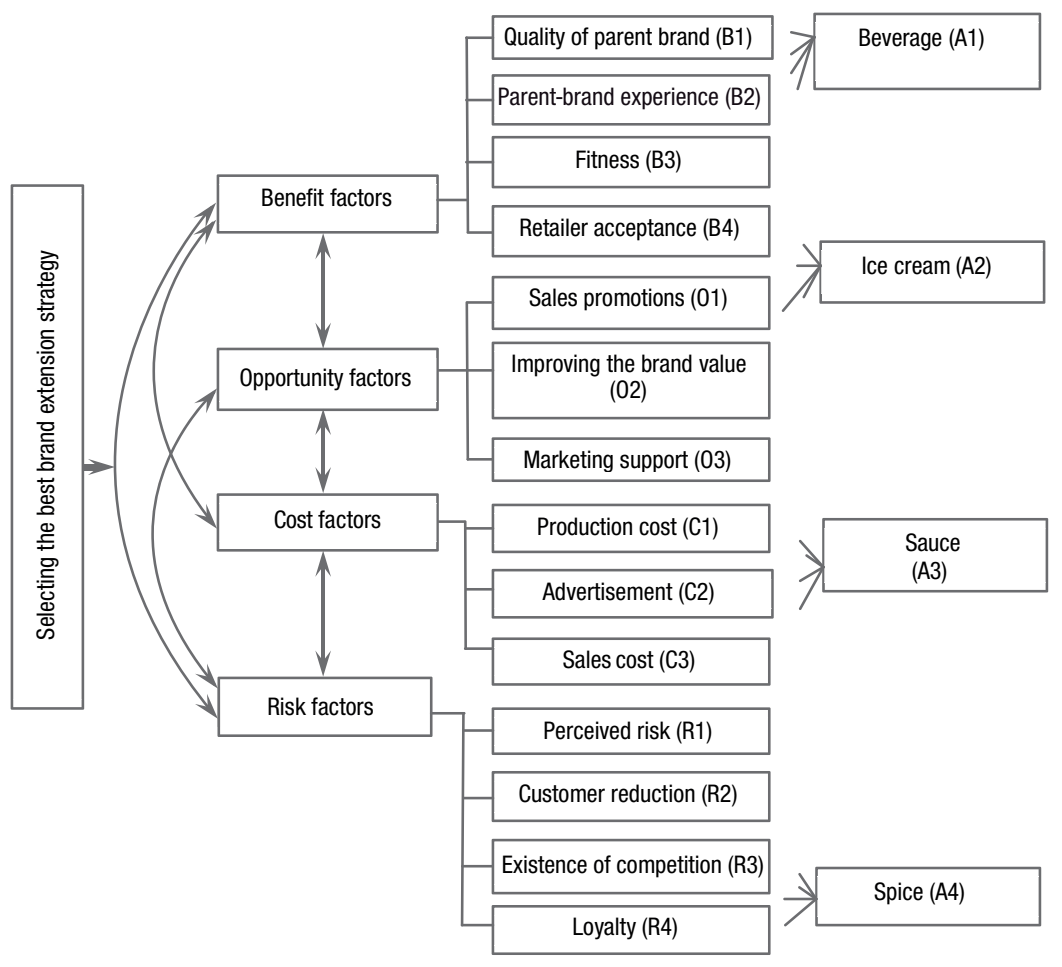

Fig. 4. Structure of the brand extension problem 
to their relative importance toward their upper criterion. Each decision maker evaluates the criteria under consideration by using two-by-two comparisons. In order to make a comparison between two components, Saaty's (1-9) scale (Saaty 1980) is employed, where 1 represents no difference between the two components and 9 represents overwhelming dominance of the component under consideration (row component) over the comparison component (column component). Likewise, the reverse comparison between the components is routinely determined by a reciprocal value. An example of the pairwise comparison matrix for the main criteria (BOCR factors) is depicted in Table 2.

Table 2. A sample of comparison matrix for the BOCR factors

\begin{tabular}{lcccc}
\hline BOCR factors & B & O & C & R \\
\hline B & 1 & 4 & 2 & 3 \\
\hline O & 0.25 & 1 & 0.33 & 0.5 \\
\hline C & 0.5 & 3 & 1 & 2 \\
\hline $\mathrm{R}$ & 0.33 & 2 & 0.5 & 1 \\
\hline
\end{tabular}

Since different decision makers have a different background, they look at the problem from divergent angles; consequently, their judgments are be dissimilar. After gathering information with the help of a questionnaire, the pair-wise comparison matrices are aggregated into the final aggregated matrices by using the geometric mean technique. This method can be used to aggregate different judgments from several experts as follows:

$$
a_{i j(g p)}=\left(a_{i j 1} \times a_{i j 2} \times a_{i j h} \times a_{i j H}\right)^{\frac{1}{H}}=\left(\prod_{h=1}^{H} a_{i j h}\right)^{\frac{1}{H}},
$$

where $a_{i j h}$ is an element of the decision matrix evaluated by decision maker $h$; $a_{i j(g p)}$ is the geometric mean of the values determined by the expert team; and $H$ is the total number of evaluators. Table 3 shows the final matrix for main and sub-criteria. In order to valid the matrices, the group consistency index (GCI) is calculated and then the group consistency ratio (GCR) is computed as indicated in the last column of Table 3.

The GCI can be mathematically defined as:

$$
G C I=\left(\lambda_{\max }-n\right) / n
$$

where $\lambda_{\max }$ is the largest eigenvalue; and $n$ is the number of the criteria under consideration. The GCR is obtained as:

$$
\mathrm{GCR}=\mathrm{GCI} / \mathrm{RCI} \text {. }
$$

The Random Consistency Index (RCI), derived from a randomly generated square matrix, is shown in Table 4. The group judgment is consistent provided that the GCR is less than 0.1 . 


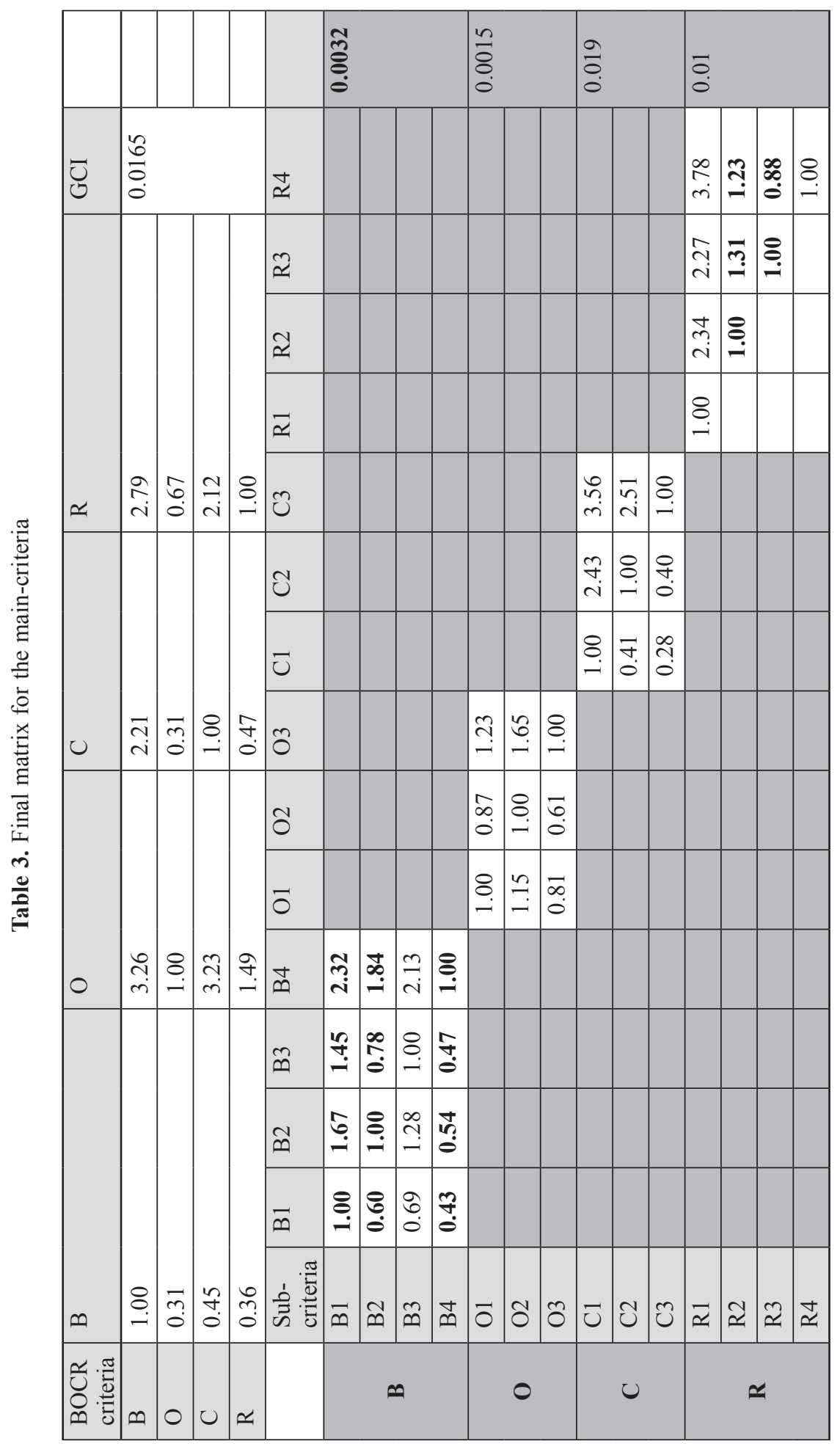


Table 4. The Random Consistency Index (Saaty 1980)

\begin{tabular}{lccccccccccccc}
\hline $\mathbf{n}$ & 3 & 4 & 5 & 6 & 7 & 8 & 9 & 10 & 11 & 12 & 13 & 14 & 15 \\
\hline $\mathbf{R C I}$ & 0.58 & 0.90 & 1.12 & 1.24 & 1.32 & 1.41 & 1.45 & 1.49 & 1.51 & 1.48 & 1.56 & 1.57 & 1.59 \\
\hline
\end{tabular}

To show how interdependency among the main-criteria can influence the difference of priority weights, the impact of each criterion on every other factor using pairwise comparison process is carried out. According to the aforementioned process, pairwise comparison matrices based on group decision making using the geometric mean technique are formed for the BOCR factors as depicted in Tables 5-8.

Table 5. The inner dependence matrix of the BOCR factors with respect to "B"

\begin{tabular}{llllc}
\hline $\mathrm{B}$ & $\mathrm{O}$ & $\mathrm{C}$ & $\mathrm{R}$ & Relative importance weights \\
\hline $\mathrm{O}$ & 1 & 0.64 & 0.87 & 0.271 \\
\hline $\mathrm{C}$ & 1.56 & 1 & 1.04 & 0.388 \\
\hline $\mathrm{R}$ & 1.15 & 0.96 & 1 & 0.341 \\
\hline $\mathrm{GCR}=0.005$ & & & \\
\hline
\end{tabular}

Table 6. The inner dependence matrix of the BOCR factors with respect to "O"

\begin{tabular}{llllc}
\hline $\mathrm{O}$ & $\mathrm{B}$ & $\mathrm{C}$ & $\mathrm{R}$ & Relative importance weights \\
\hline $\mathrm{B}$ & 1 & 1.23 & 1.64 & 0.410 \\
\hline $\mathrm{C}$ & 0.81 & 1 & 1.57 & 0.352 \\
\hline $\mathrm{R}$ & 0.61 & 0.64 & 1 & 0.237 \\
\hline $\mathrm{GCR}=0.002$ & & & \\
\hline
\end{tabular}

Table 7. The inner dependence matrix of the BOCR factors with respect to " $\mathrm{C}$ "

\begin{tabular}{llllc}
\hline $\mathrm{C}$ & $\mathrm{B}$ & $\mathrm{O}$ & $\mathrm{R}$ & Relative importance weights \\
\hline $\mathrm{B}$ & 1 & 2.43 & 1.78 & 0.505 \\
\hline $\mathrm{O}$ & 0.81 & 1 & 0.67 & 0.202 \\
\hline $\mathrm{R}$ & 0.61 & 0.64 & 1 & 0.293 \\
\hline $\mathrm{GCR}=0.0005$ & & & \\
\hline
\end{tabular}

Table 8. The inner dependence matrix of the BOCR factors with respect to " $R$ "

\begin{tabular}{llllc}
\hline R & B & O & C & Relative importance weights \\
\hline $\mathrm{B}$ & 1 & 1.33 & 1.13 & 0.380 \\
\hline $\mathrm{O}$ & 0.81 & 1 & 0.96 & 0.297 \\
\hline $\mathrm{C}$ & 0.61 & 0.64 & 1 & 0.323 \\
\hline $\mathrm{GCR}=0.001$ & & & \\
\hline
\end{tabular}

The relative weights of the BOCR factors are listed in the last row of Tables 5-8. The inner dependence matrix is formed as follows: 


$$
\left[\begin{array}{cccc}
1.00 & 0.41 & 0.505 & 0.38 \\
0.271 & 1.00 & 0.202 & 0.297 \\
0.388 & 0.352 & 1.00 & 0.323 \\
0.341 & 0.237 & 0.293 & 1.00
\end{array}\right] .
$$

Using the inner dependence weights resulted from this step and the dependence weights derived from the previous step, the priority weights for the BOCR factors is yielded as follows:

$$
\left[\begin{array}{cccc}
1.00 & 0.41 & 0.505 & 0.38 \\
0.271 & 1.00 & 0.202 & 0.297 \\
0.388 & 0.352 & 1.00 & 0.323 \\
0.341 & 0.237 & 0.293 & 1.00
\end{array}\right] \times\left[\begin{array}{c}
0.453 \\
0.109 \\
0.286 \\
0.151
\end{array}\right]=\left[\begin{array}{c}
0.35 \\
0.167 \\
0.274 \\
0.209
\end{array}\right] .
$$

The results change from 0.453 to $0.35,0.109$ to $0.167,0.286$ to 0.274 , and 0.151 to 0.209 for the priority values of factors B, O, C and R, respectively. From the above matrix, it can be obvious that the results are significantly different from when the interdependent weights are not taken into account. It can be seen that the largest changes are in "O" and "R" criteria. Without considering the dependency among the criteria, "B" has the highest intensity among all criteria. However, when taking the interdependency into account, the intensity of " $\mathrm{B}$ " is completely different. The " $\mathrm{B}$ " criterion became the most important factor for evaluating brand extension strategies because " $\mathrm{B}$ " criterion influences other criteria more significantly.

Therefore, the priority weights for main and sub-criteria are computed as listed in Table 9.

Table 9. Priority weights for the main and sub-criteria

\begin{tabular}{lccc}
\hline BOCR criteria & Sub-criteria & Local weights & Global weights \\
\hline $\mathrm{B}$ & & 0.35 & - \\
\hline & $\mathrm{B} 1$ & 0.362 & 0.127 \\
\hline & $\mathrm{B} 2$ & 0.226 & 0.079 \\
\hline & $\mathrm{B} 3$ & 0.275 & 0.096 \\
\hline $\mathrm{B} 4$ & 0.136 & 0.048 \\
\hline & $\mathrm{B}$ & 0.167 & - \\
\hline & $\mathrm{O} 1$ & 0.335 & 0.056 \\
\hline & $\mathrm{O} 2$ & 0.406 & 0.068 \\
\hline $\mathrm{C}$ & $\mathrm{O}$ & 0.259 & 0.043 \\
\hline & & 0.274 & - \\
\hline & $\mathrm{C} 1$ & 0.576 & 0.158 \\
\hline $\mathrm{C} 2$ & 0.286 & 0.078 \\
\hline & $\mathrm{C} 3$ & 0.137 & 0.038 \\
\hline & & 0.209 & - \\
\hline & $\mathrm{R} 1$ & 0.503 & 0.105 \\
\hline & $\mathrm{R} 2$ & 0.198 & 0.041 \\
\hline & $\mathrm{R} 3$ & 0.146 & 0.031 \\
\hline & $\mathrm{R} 4$ & 0.153 & 0.032 \\
\hline
\end{tabular}




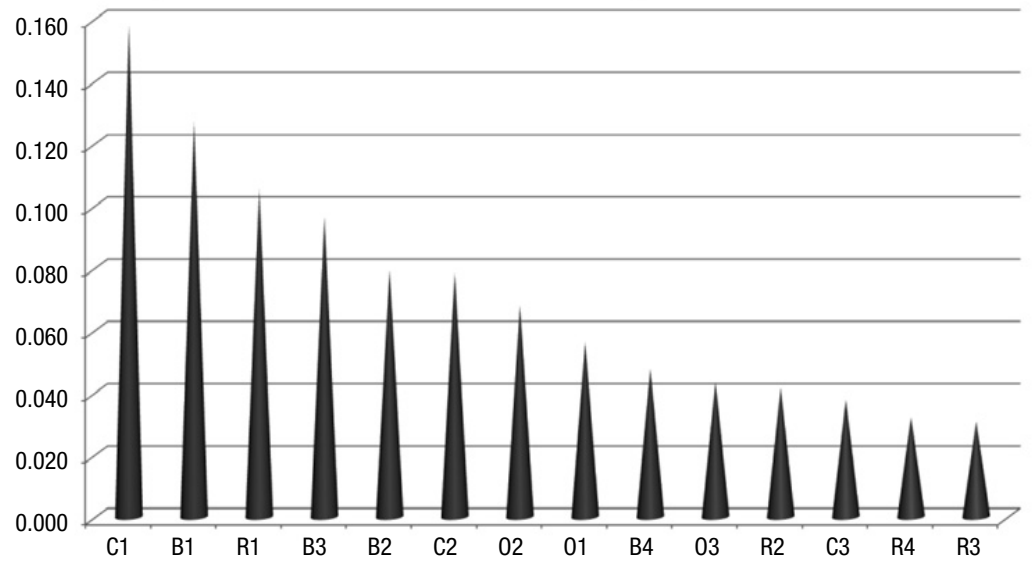

Fig. 5. Final ranking of the criteria

Table 10. A sample of fuzzy evaluation matrix evaluated by one of the experts

\begin{tabular}{lcccc}
\hline & A1 & A2 & A3 & A4 \\
\hline B1 & F & VG & G & P \\
\hline B2 & G & G & VP & F \\
\hline B3 & G & VG & G & F \\
\hline B4 & VG & G & F & G \\
\hline O1 & VG & VG & G & G \\
\hline O2 & F & F & G & VG \\
\hline O3 & G & F & F & F \\
\hline C1 & VG & G & F & F \\
\hline C2 & F & VG & G & G \\
\hline C3 & F & G & F & G \\
\hline R1 & VG & F & G & G \\
\hline R2 & G & F & F & P \\
\hline R3 & P & G & F & G \\
\hline R4 & VG & F & VP & P \\
\hline & & & &
\end{tabular}

Based on the results derived from the model, "C1" is weighted more heavily $(0.158)$ than the other criteria. The results also reveal that the criterion "R3" $(0.031)$ is less important than the other criteria. The assessment results for the priority weights of the evaluation criteria under consideration are decreasingly depicted in Figure 5.

In the next step of the proposed model, evaluators are asked to build the decision matrix by comparing the alternatives under each criterion by using the scale given in Table 1 and Figure 2. For the evaluation indicators under benefit and opportunity factors (B1, $\mathrm{B} 2, \mathrm{~B} 3, \mathrm{~B} 4, \mathrm{O} 1, \mathrm{O} 2$, and $\mathrm{O} 3$ ), the higher the score, the better the performance of the brand extension strategy is. Whereas, for the indicators under cost and risk factors $(\mathrm{C} 1$, $\mathrm{C} 2, \mathrm{C} 3, \mathrm{R} 1, \mathrm{R} 2, \mathrm{R} 3$, and R4), the higher the score, the worse the performance of the brand extension strategy is. A sample of the fuzzy decision matrix evaluated by one of 
Table 11. Aggregated evaluation matrix

\begin{tabular}{cccccc}
\hline & A0 & A1 & A2 & A3 & A4 \\
\hline B1 & $(1,1,1)$ & $(0.34,0.49,0.64)$ & $(0.59,0.74,0.89)$ & $(0.53,0.68,0.83)(0.24,0.39,0.54)$ \\
\hline B2 & $(1,1,1)$ & $(0.46,0.61,0.76)$ & $(0.47,0.62,0.77)$ & $(0.12,0.27,0.42)(0.37,0.52,0.67)$ \\
\hline B3 & $(1,1,1)$ & $(0.51,0.66,0.81)$ & $(0.62,0.77,0.92)$ & $(0.43,0.58,0.73)(0.33,0.48,0.63)$ \\
\hline B4 & $(1,1,1)$ & $(0.62,0.77,0.92)$ & $(0.42,0.57,0.72)$ & $(0.36,0.51,0.66)(0.46,0.61,0.76)$ \\
\hline O1 & $(1,1,1)$ & $(0.58,0.73,0.88)$ & $(0.61,0.76,0.91)$ & $(0.44,0.59,0.74)(0.51,0.66,0.81)$ \\
\hline O2 & $(1,1,1)$ & $(0.41,0.56,0.71)$ & $(0.36,0.51,0.66)$ & $(0.48,0.63,0.78)(0.64,0.79,0.94)$ \\
\hline O3 & $(1,1,1)$ & $(0.48,0.63,0.78)$ & $(0.29,0.44,0.59)$ & $(0.32,0.47,0.62)(0.38,0.53,0.68)$ \\
\hline C1 & $(0.29,0.29,0.29)$ & $(0.57,0.72,0.87)$ & $(0.46,0.61,0.76)$ & $(0.37,0.52,0.67)(0.29,0.44,0.59)$ \\
\hline C2 & $(0.32,0.32,0.32)$ & $(0.32,0.47,0.62)$ & $(0.62,0.77,0.92)$ & $(0.46,0.61,0.76)$ & $(0.45,0.6,0.75)$ \\
\hline C3 & $(0.38,0.38,0.38)$ & $(0.41,0.56,0.71)$ & $(0.45,0.6,0.75)$ & $(0.38,0.53,0.68)(0.49,0.64,0.79)$ \\
\hline R1 & $(0.36,0.36,0.36)$ & $(0.63,0.78,0.93)$ & $(0.36,0.51,0.66)$ & $(0.41,0.56,0.71)(0.51,0.66,0.81)$ \\
\hline R2 & $(0.23,0.23,0.23)$ & $(0.47,0.62,0.77)$ & $(0.41,0.56,0.71)$ & $(0.33,0.48,0.63)(0.23,0.38,0.53)$ \\
\hline R3 & $(0.13,0.13,0.13)$ & $(0.13,0.28,0.43)$ & $(0.52,0.67,0.82)$ & $(0.38,0.53,0.68)(0.46,0.61,0.76)$ \\
\hline R4 & $(0.17,0.17,0.17)$ & $(0.65,0.8,0.95)$ & $(0.37,0.52,0.67)$ & $(0.17,0.32,0.47)(0.27,0.42,0.57)$ \\
\hline & & & & \\
\hline
\end{tabular}

the experts is depicted in Table 10. Then, the aggregated fuzzy performance ratings of the feasible alternatives with respect to each criterion are computed by Eq. (4) and the results are presented in Table 11. By multiplying the normalized decision matrix and the weights derived from the ANP technique, the weighted normalized decision matrix is obtained as shown in Table 12.

After calculating the weighted normalized decision matrix, the values of optimality function for the brand extension strategies must be determined by using Eq. (12) as presented in Table 13.

In order to make a comparison between the performances of the alternatives, the values resulting from optimality function are transferred into crisp value by using the defuzzification process. Finally, after calculating the utility degree of each alternative by using Eq. (14), the alternatives are ranked in descending order and the alternative with maximum value of $\mathrm{Ki}$ is selected as the best choice. According to $\mathrm{Ki}$ values, the ranking of the alternatives in descending order are A2, A3, A4, and A1. The proposed model indicates that ice cream (A2) is the best method with $\mathrm{Ki}$ value of 0.808 . Rankings of the alternatives according to Ki values are listed in the last row of Table 13. 


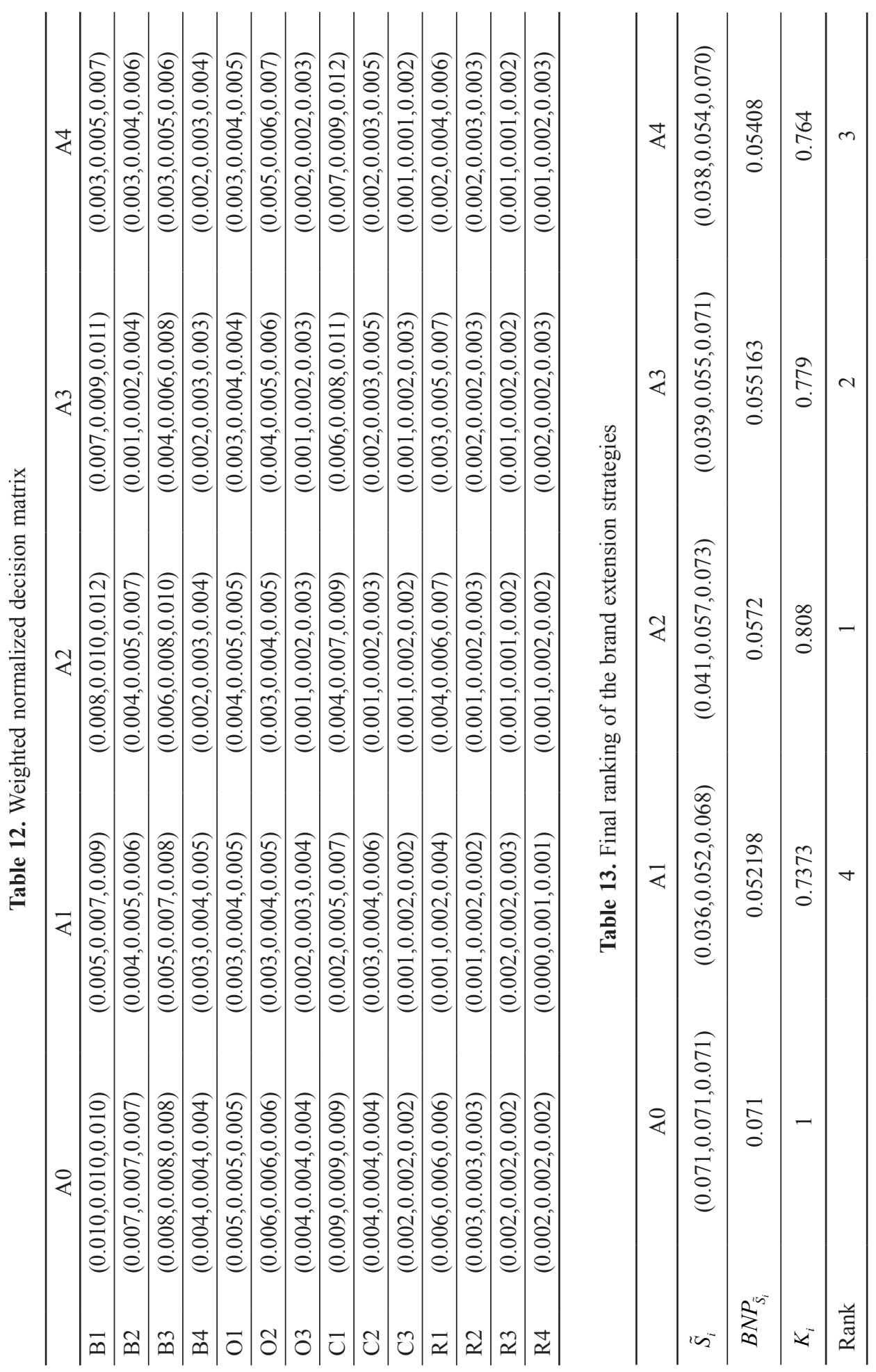




\section{Conclusions}

Group decision making under fuzzy environment provides a powerful tool for evaluating and prioritizing the feasible alternatives under their preference with respect to the criteria being often in conflicting with each other. This paper proposes a new integrated model based on ANP and fuzzy ARAS methods that is capable of handling both subjective judgment and objective information in the process of formulating a decision making problem. However, according to the inherent complexity and less of information in real world problems, the output of the proposed model is more adapted with real world terms. The proposed model integrates ANP and fuzzy ARAS models under the group decision making. The first is used to interpret the interrelationship into weights of relationship. The latter is based on the concept that the phenomena of complicated world could be understood by using simple relative comparisons for solving the MCDM problems with multi-judges in the term of vagueness. In the system of the proposed model, the ANP technique is utilized to calculate the relative weights of the evaluation indicators and fuzzy ARAS is used to obtain the performance ratings of the feasible alternatives by using linguistic terms. In order to prove the validity and suitability of the proposed model, a real case study is illustrated for the brand extension strategy selection in the food industry. Although the proposed model is employed for the strategic decisions, it can be applied for making the best decision in any other area of engineering and management.

\section{References}

Aaker, D. A. 1990. Brand extensions: 'the good, the bad, and the ugly', Sloan Management Review Summer (1990): 47-56.

Azimi, R.; Yazdani-Chamzini, A.; Fouladgar, M. M.; Zavadskas, E. K.; Basiri, M. H. 2011. Ranking the strategies of mining sector through ANP and TOPSIS in a SWOT framework, Journal of Business Economics and Management 12(4): 670-689. http://dx.doi.org/10.3846/16111699.2 011.626552

Bakshi, T.; Sarkar, B. 2011. MCA based performance evaluation of project selection, International Journal of Software Engineering \& Applications (IJSEA) 2(2): 14-22. http://dx.doi. org/10.5121/ijsea.2011.2202

Bakshi, T.; Sinharay, A. 2011. An integrated novel approach in MCDM under fuzziness, International Journal of Computer \& Communication Technology 2: 36-43.

Belton, V.; Stewart, T. J. 2002. Multiple criteria decision analysis. Dordrecht: Kluwer Academic Publishers. http://dx.doi.org/10.1007/978-1-4615-1495-4

Chen, V. Y. C.; Lien, H. P.; Liu, C. H.; Liou, J. J. H.; Tzenge, G. H.; Yang, L. S. 2011. Fuzzy MCDM approach for selecting the best environment-watershed plan, Applied Soft Computing 11(1): 265-275. http://dx.doi.org/10.1016/j.asoc.2009.11.017

Chung, S.; Lee, A. H. I.; Pearn, W. L. 2005. Analytic network process (ANP) approach for product mix planning in semiconductor fabricator, International Journal Production Economics 96: 15-36. http://dx.doi.org/10.1016/j.ijpe.2004.02.006

Dadelo, S.; Turskis, Z.; Zavadskas, E. K.; Dadeliene, R. 2012. Multiple criteria assessment of elite security personnel on the basis of ARAS and expert methods, Economic Computation and Economic Cybernetics Studies and Research 46(4): 65-87. 
Estes, Z.; Gibbert, M.; Guest, D.; Mazursky, D. 2012. A dual-process model of brand extension: taxonomic feature-based and thematic relation-based similarity independently drive brand extension evaluation, Journal of Consumer Psychology 22: 86-101. http://dx.doi.org/10.1016/j. jcps.2011.11.002

Fouladgar, M. M.; Yazdani-Chamzini, A.; Zavadskas, E. K.; Moini, S. H. H. 2012. A new hybrid model for evaluating the working strategies: case study of a construction company, Technological and Economic Development of Economy 18(1): 164-188. http://dx.doi.org/10.3846/202949 13.2012.667270

Keller, K. L. 1998. Strategic brand management: building, measuring, and managing brand equity. Hemel-Hempstead, UK: Prentice Hall.

Kutut, V.; Zavadskas, E. K.; Lazauskas, M. 2013. Assessment of priority options for preservation of historic city centre buildings using MCDM (ARAS), Procedia Engineering 57: 657-661. http://dx.doi.org/10.1016/j.proeng.2013.04.083

Lee, H.; Kim, M. S.; Park, Y. 2012. An analytic network process approach to operationalization of five forces model, Applied Mathematical Modelling 36(4): 1783-1795. http://dx.doi. org/10.1016/j.apm.2011.09.012

Presley, A.; Meade, L. 1999. Strategic alignment and IT investment selection using the Analytic Network Process, in The Americas Conference on information systems, Milwaukee WI.

Robbins, S. P. 1994. Management. Prentice, New Jersey: Prentice Hall Inc.

Saaty, T. L. 1996. Decision making with dependence and feedback: the analytic network process. Pittsburgh: RWS Publications.

Saaty, T. L. 1980. The analytic hierarchy process. New York: McGraw-Hill.

Sjodin, H.; Torn, F. 2006. When communication challenges brand associations: a framework for understanding consumer responses to brand image incongruity, Journal of Consumer Behaviour 5(1): 32-42. http://dx.doi.org/10.1002/cb.44

Sotirov, G. R.; Krasteva, E. B. 1994. An approach to group decision making under uncertainty with application to project selection, Annals of Operations Research 51(3): 115-126. http:// dx.doi.org/10.1007/BF02032480

Tauber, E. M. 1981. Brand franchise extensions: new products benefit from existing brand names, Business Horizons 24(2): 36-41. http://dx.doi.org/10.1016/0007-6813(81)90144-0

Turskis, Z.; Lazauskas, M.; Zavadskas, E. K. 2012. Fuzzy multiple criteria assessment of construction site alternatives for non-hazardous waste incineration plant in Vilnius city, applying ARAS-F and AHP methods, Journal of Environmental Engineering and Landscape Management 20(2): 110-120. http://dx.doi.org/10.3846/16486897.2011.645827

Turskis, Z.; Zavadskas, E. K. 2010. A new fuzzy additive ratio assessment method (ARAS-F). Case study: the analysis of fuzzy multiple criteria in order to select the logistic centers location, Transport 25(4): 423-432. http://dx.doi.org/10.3846/transport.2010.52

Wu, C. S.; Lin, C. T.; Lee, C. 2010. Optimal marketing strategy: a decision-making with ANP and TOPSIS, International Journal of Production Economics 127: 190-196. http://dx.doi. org/10.1016/j.ijpe.2010.05.013

Wu, H. Y.; Tzeng, G. H.; Chen, Y. H. 2009. A fuzzy MCDM approach for evaluating banking performance based on balanced scorecard, Expert Systems with Applications 36(6): 10135-10147. http://dx.doi.org/10.1016/j.eswa.2009.01.005

Yazdani-Chamzini, A.; Yakhchali, S. H. 2012. Tunnel Boring Machine (TBM) selection using fuzzy multicriteria decision making methods, Tunnelling and Underground Space Technology 30: 194-204. http://dx.doi.org/10.1016/j.tust.2012.02.021 
Yazgan, H. R.; Boran, S.; Goztepe, K. 2010. Selection of dispatching rules in FMS: ANP model based on BOCR with choquet integral, International Journal Advanced Manufacturing Technology 49: 785-801. http://dx.doi.org/10.1007/s00170-009-2416-x

Yüksel, İ; Dağdeviren, M. 2007. Using the analytic network process (ANP) in a SWOT analysis - a case study for a textile firm, Information Sciences 177: 3364-3382. http://dx.doi. org/10.1016/j.ins.2007.01.001

Zadeh, L. A. 1965. Fuzzy set, Information and Control 8: 338-353. http://dx.doi.org/10.1016/ S0019-9958(65)90241-X

Zavadskas, E. K.; Turskis, Z. 2010. A new additive ratio assessment (ARAS) method in multicriteria decision making, Technological and Economic Development of Economy 16(2): 159-172. http://dx.doi.org/10.3846/tede.2010.10

Zavadskas, E. K.; Turskis, Z.; Vilutiene, T. 2010. Multiple criteria analysis of foundation instalment alternatives by applying Additive Ratio Assessment (ARAS) method, Archives of Civil and Mechanical Engineering 10(3): 123-141. http://dx.doi.org/10.1016/S1644-9665(12)60141-1

Zavadskas, E. K.; Vainiūnas, P.; Turskis, Z.; Tamošaitienė, J. 2012. Multiple criteria decision support system for assessment of projects managers in construction, International Journal of Information Technology \& Decision Making 11(2): 501-520. http://dx.doi.org/10.1142/ S0219622012400135

Mahmoud ZAMANI is a PhD student in innovation at The University of Teheran Management School, Teheran, Iran. He is the author of more than 5 research papers. His interests include innovation, technology strategy, marketing and MCDM methods.

Arefeh RABBANI graduated with MSc from the management and accounting faculty at Allame Tabatabaee University, Teheran, Iran in 2013. Her interests include innovation, human resource management (HRM), organization learning and Strategy.

Abdolreza YAZDANI-CHAMZINI. Master of Science in the Department of Mining Engineering, research assistant of Teheran University, Teheran-Iran. Author of more than 46 research papers. In 2011, he graduated from the Science and Engineering Faculty at Tarbiat Modares University, Teheran-Iran. His research interests include decision making, forecasting, modelling, and optimization.

Zenonas TURSKIS. Professor, senior research fellow at the Construction Technology and Management Laboratory of Vilnius Gediminas Technical University, Lithuania. His research interests include building technology and management, decision-making theory, computer-aided design and expert systems. Author of more than 90 research papers. 